\title{
EDITORIALS
}

\section{Primary Non-adherence of Medications: lifting the veil on prescription-filling behaviors}

\author{
Matthew D. Solomon, MD, $P h D^{7}$ and Sumit R. Majumdar, MD, MPH, FRCPC, FACP ${ }^{2}$ \\ 'Stanford University, Stanford, CA, USA; ${ }^{2}$ University of Alberta, Alberta, Canada.
}

$\mathrm{J}$ Gen Intern Med 25(4):280-1

DOI: $10.1007 / \mathrm{s} 11606-010-1286-0$

(c) Society of General Internal Medicine 2010

$\mathrm{E}$ conomists say that consumers "vote with their feet". That is, in order to understand human behavior, we can interpret people's underlying preferences by observing their choices. Unfortunately, in much of the social sciences, researchers are limited in their ability to directly observe people's choices. This is particularly true when studying the problem of medication adherence. Medication "adherence" is defined as the degree of patient compliance with providers' recommendations about the daily timing, dosage, and frequency of medication use. This differs from "persistence," which refers to whether patients continue a treatment for the prescribed duration. Both are difficult to study. Aside from watching patients drop pills into their mouths and swallow them every day (which is clearly infeasible except for extreme circumstances such as directly observed treatment for multidrug resistant tuberculosis or HIV) researchers are left to examine surrogate measures of adherence behaviors.

Typically, claims data have been mined to measure the frequency and timing of prescription refills to calculate metrics such as the medication possession ratio or gaps in therapy, techniques that make the most of available information, but provide a limited glimpse into a patient's course of treatment. Physicians are left to wonder, "What did the patient really do with all the medication he picked up? Did she split pills into two to reduce side effects or save money? Is the bottle sitting full on the bathroom shelf? Did the patient start using a Canadian, Mexican, or Internet pharmacy, and is that why refills seem to have ceased?" And finally, and perhaps most importantly: "Were there prescriptions written that were never even filled in the first place?"

The answer to this final question has been a conspicuously missing piece in the medication adherence story. When patients do not even fill a new prescription, it is called "primary" nonadherence to distinguish it from what is far more commonly studied, namely "secondary" nonadherence (i.e., when prescriptions are filled, but the medication is not taken as prescribed) and lack of persistence (i.e., when patients, who may have perfect primary and secondary adherence, self-discontinue therapy by not refilling their prescriptions). The study of primary nonadherence has been lacking because researchers have been unable to effectively

Published online March 2, 2010 track the entire lifespan of a new prescription. Until recently, prescriptions were almost exclusively hand-written on paper pads. Once a patient left the office with a paper prescription, it was either filled at a pharmacy, creating a traceable (sometimes computerized) administrative record, or it went unfilled with no one the wiser. We already know that poor adherence (mostly secondary nonadherence and lack of persistence) to medications is associated with worse health outcomes ${ }^{1,2}$ and increased health care $\operatorname{costs}^{3}$. Furthermore, many factors associated with poor adherence have been identified, including but not limited to increased cost-sharing ${ }^{4}$, pill burden and regimen complexity, side-effects, and patient beliefs about whether drugs actually improve their health ${ }^{5}$. Again, it is noteworthy that these studies almost universally measure the effect of interruptions (secondary nonadherence) or discontinuations (lack of persistence) with chronic medical therapies that have actually been started.

Our lack of insight into the prevalence and magnitude of primary medication nonadherence also means that we may have been missing a major target for interventions to improve the quality and outcomes of patient care. Substantial evidence tells us that many patients-up to one-third or more-are aware they have a medical condition but are still poorly controlled or untreated ${ }^{6,7}$. Empirically, these numbers seem too large to be explained by skipped doses and early discontinuation. Obviously, unless a patient fills a first prescription, they will not reap the benefits of ongoing treatment. Although some research has explored the factors associated with filling a first prescription and sticking with it after a new diagnosis ${ }^{7,8}$, these studies have also relied on claims data, and could not completely or accurately identify true primary nonadherence. One recent study restricted to elderly Canadians from one province who survived a myocardial infarction demonstrated 10-20\% primary nonadherence with life-saving cardiac medications $^{9}$. To our knowledge this is also the only study that has linked primary nonadherence to downstream major adverse events.

In this issue of the Journal, Fischer et al. begin to lift the veil on how often patients do not fill their prescriptions by measuring primary nonadherence for a large population of commercially insured outpatients ${ }^{10}$. Using a novel electronic prescription writing initiative in two large Massachusetts health plans, they tracked the difference between prescriptions written electronically in a physician's office-a critical data element previously unavailable to most researchers-and prescriptions actually filled at pharmacies on the basis of insurance claims. They collected some data on the medications, the patients, and the participating physicians to identify characteristics that may be associated with better or worse adherence. 
Briefly, they found that almost one-quarter of all prescriptions (electronically) written went unfilled, and, crucially, that $28.3 \%$ of all new (that is to say first) prescriptions went unfilled. After exploring multiple drug classes, they found that the least filled class was pain medications, with less than half of all prescriptions filled. However, even among new prescriptions for medicines used to treat chronic conditions associated with increased cardiovascular risk, such as hypertension, diabetes, and dyslipidemia, one-third of all new prescriptions went unfilled. These numbers are consistent with epidemiologic data about the lack of adequate control of these prevalent and deadly cardiovascular risk factors and may help to explain issues related to their undertreatment.

Fischer and colleagues also begin to provide us with some insights into patient behavior: for many reasons, people avoid taking prescription medicines even when advised by a physician and after the prescription has been written. A doctrine in our profession is to do no harm, and medicines tend to be prescribed when physicians believe that the benefits outweigh the risks. Thus, there are clearly many people who, in our estimation, are not reaping potential health benefits. Because of our poor understanding of these problems, researchers have struggled to optimally design effective interventions to help ensure that patients are getting the pharmaceutical care they need by filling their first prescription, adhering to the medication as directed, and then persisting with treatment ${ }^{2,4}$. Attacking primary nonadherence must be a focus of future interventions, health policies, and careful research. There is simply too much achievable benefit not being achieved.

For now, those of us prescribing on the front lines should begin to focus efforts on the encounters when patients are first diagnosed with a new chronic condition and prescribed their initial treatment regimens. This is certainly crucial for silent conditions such as hypertension, diabetes, and dyslipidemia. Although Fischer et al.'s study suggests that prescriptions written by primary care physicians are filled at a higher rate than prescriptions written by specialists, we should not necessarily take much comfort in this finding-the specialists and prescriptions written by these specialists are likely far too heterogeneous to make truly convincing comparisons with primary care physicians. Nevertheless, primary care physicians are crucial to the therapeutic alliance and so must do all that they can to ensure primary adherence.

Finally, though the evidence is somewhat mixed regarding the benefits of electronic prescribing ${ }^{11,12}$, and such systems have not yet been convincingly demonstrated to either improve health outcomes or reduce costs, health information systems with e-prescribing functionality are in all of our futures. With new insights gained from studies such as Fischer et al., perhaps these new systems can be better designed and engineered to help improve initiation and adherence and persistence. Computerized telephone calls that remind patients to pick up a prescription are one possibility, as might be having far greater communication linkages between physicians and the dispensing pharmacists. In addition, future researchers can exploit the adoption of electronic medical records and other health information technologies to provide a more complete picture about the overall patient experience with medical therapy. Instead of relying on surrogates of behavior, we will be able to better directly observe people "voting with their feet"-and then figure out ways to get them to vote differently.

Acknowledgements: The authors have no conflicts of interest to disclose. SRM receives salary support from the Alberta Heritage Foundation for Medical Research.

Corresponding Author: Matthew D. Solomon, MD, PhD; Stanford University, 300 Pasteur Drive, Falk Bldg-CVC, Stanford, CA 94305, USA (e-mail: msolomon@stanford.edu).

\section{REFERENCES}

1. Ho PM, Rumsfeld JS, Masoudi FA, et al. Effect of medication nonadherence on hospitalization and mortality among patients with diabetes mellitus. Arch Int Med. 2006;166:1836-41.

2. Simpson SH, Eurich DT, Majumdar SR, Padwal RS, Tsuyuki RT, Varney J, Johnson JA. A meta-analysis of the association between adherence to drug therapy and mortality. BMJ. 2006;332:15-9.

3. McCombs JS, Nichol MB, Newman CM, Sclar DA. The costs of interrupting antihypertensive drug therapy in a Medicaid population. Med Care. 1994;32(3):214-26.

4. Goldman DP, Joyce GF, Zheng Y. Prescription Drug Cost Sharing: Associations With Medication and Medical Utilization and Spending and Health. JAMA. 2007;298:61-9.

5. Safran DG, Neuman P, Schoen C, Kitchman MS, Wilson IB, Cooper B, Li A, Chang H, Rogers WH. Prescription Drug Coverage And Seniors: Findings From A 2003 National Survey. Health Aff. 2005 Jan-Jun;Suppl Web Exclusives:W5-152-W5-166.

6. Natarajan S, Nietert PJ. National trends in screening, prevalence, and treatment of cardiovascular risk factors. Prev Med. 2003;36(4):389-97.

7. Solomon MD, Goldman DP, Joyce GF, Escarce JJ. Cost sharing and the initiation of drug therapy for the chronically ill. Arch Intern Med. 2009;169(8):740-8

8. Gibson TB, Mark TL, McGuigan KA, Axelsen K, Wang S. The effects of prescription drug copayments on statin adherence. Am J Manag Care. 2006; 12:509-17.

9. Jackevicius CA, Li P, Tu JV. Prevalence, predictors, and outcomes of primary nonadherence after acute myocardial infarction. Circulation. 2008;117(8): 1028-36.

10. Fischer MA, Stedman MR, Li J, Vogeli C, Shrank WH, Brookhart MA, Weissman JS. Primary medication non-adherence: analysis of 195,930 electronic prescriptions. J Gen Intern Med. 2010; XXXXXXI.

11. Bell DS, Marken RS, Meili RC, Wang CJ, Rosen M, Brook RH. RAND Electronic Prescribing Expert Advisory Panel. Recommendations for comparing electronic prescribing systems: results of an expert consensus panel. Health Aff (Millwood). 2004 Jan-Jun;Suppl Web Exclusives: W4-305-17.

12. Gandhi TK, Weingart SN, Seger AC, Borus J, Burdick E, Poon EG, Leape LL, Bates DW. Outpatient prescribing errors and the impact of computerized prescribing. J Gen Intern Med. 2005;20(9):837-41. 